\title{
Detection and Location of High Impedance Faults in Distribution Systems: A Review
}

\author{
Gogula Vyshnavi ${ }^{1 *}$ and Avagaddi Prasad ${ }^{2}$ \\ Applied Renewable Energy Research Lab, Dept. of Electrical \& Electronic \\ Engineering, Sree Vidyanikethan Engineering College, Tirupati, AP, India \\ ${ }^{1}$ vyshnavigogula04@gmail.com, ${ }^{2}$ prasadavagaddi@gmail.com
}

\begin{abstract}
Power system is a combination of large and complex electrical distribution networks. Protection is a critical issue in power system for both operational and safety reasons. An efficient protection scheme must have the capability to secure, that the power system works sufficiently, and ensures the equipment and additionally the general population from hazardous over voltages. The greatest challenge for electrical engineers is to provide better protection scheme to detect and locate the high impedance faults. The methods can be divided in to two categories, simple and artificial intelligent techniques. Simple technique include discrete wavelet transform and intelligent strategies incorporate artificial neural network, support vector machine, genetic algorithm, and fuzzy logic technique. All these techniques have their own merits and drawbacks. In this work, a large portion of the methods that have been discussed about since the past and usually used to detect and locate high impedance faults in appropriation system are reviewed.
\end{abstract}

Keywords: Distribution systems, High impedance faults, High impedance fault detection and location, intelligent techniques

\section{Introduction}

High impedance faults (HIFs) can occur in to two forms. 1. A conductor breaks and falls to the ground. 2. An electrical conductor isn't isolated however just is to be associated with a high impedance object. HIF are typically connected with an electric circular segment, which may cause a fire. Because of the nonlinearity idea of the fault, the HIF current contains different repetition symphonious parts including low and high-repetition segments. It must to be noted that other system parts have likewise wide repetition sounds, in this manner the analysts have played out a few HIF tests and have contemplated the related voltage and current to get models that are used in the simulations. HIF is a group of power system disturbances that prevents the generation of sufficient current that is required to trip the overcurrent relays, due to high grounding impedance. This term is normally applied to faults in distribution networks $(15 \mathrm{kV}-25 \mathrm{kV})$. However, detection \& location procedures are additionally proposed for HIFs in distribution systems, low voltage control system, and low voltage $400 \mathrm{~Hz}$ plane circuits. HIFs are affected by various variables, to be specific, the ground surface material, surface humidity, feeder arrangement, voltage levels, climate conditions, and load compose. The two most powerful factors on the HIF attributes are: (a) surface stickiness and (b) surface material.

It is shown that higher surface humidity results in higher fault current magnitude. Moreover, HIF occurs on various materials and each results in different voltage-current characteristics. The materials that are mostly touched by down-conductors are: tree branches, lawns, gravel, stout gravel, thin gravel, asphalt, concrete, sand, crushed stone, board blocks, and cement. HIF occurring on concrete and grass surfaces. Unlike most power

Received (March 2, 2018), Review Result (June 1, 2018), Accepted (June 5, 2018) 
system faults, which primarily endanger electrical equipment, HIFs expose human safety and could also result in legal issues. Therefore, since over-current relays are unable to detect HIFs, it is a crucial task to detect these types of fault using algorithms that are specially designed to address such issues. Followed by HIF inception, the generation and accretion of combustible gas, or the evolution of the arc to close flammable material could result in fire and explosion. In addition to these hazards, there is a probability that the line crewmen or members of the public would have unintentional contact with the energized exposed conductor. Certain and comprehensive reports about the statistics of the HIFs are missing since only the faults that result in relay alarm or trip are reported. However, it is estimated that between $5 \%$ and $10 \%$ of the distribution faults are HIF $[1,2]$.

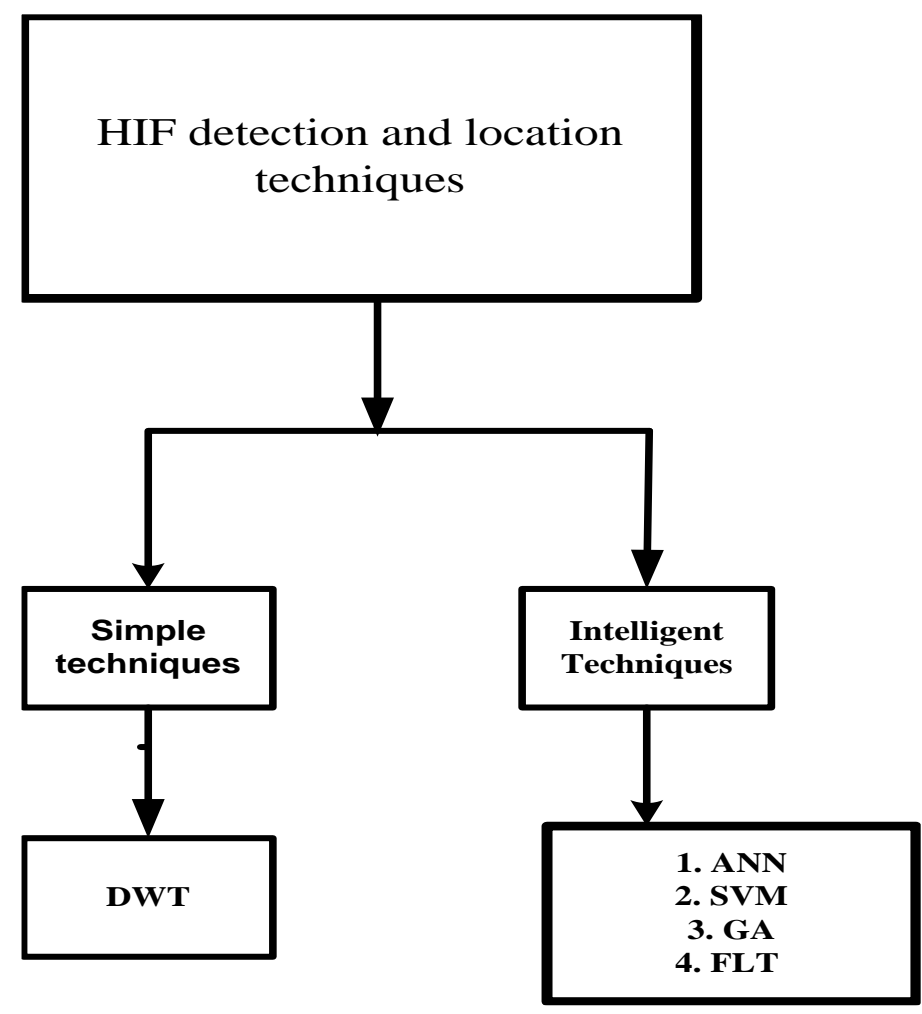

Figure 1. Overview of Detection and Location Techniques [2]

Figure 1 shows overview of detection and location technique, it has been reported that $25 \%$ of the down-conductors are not detected using the over-current relays, which are considered as HIFs. Another study increases this number up to $32 \%$ of the downconductors. All of these reports point to the fact that the HIFs are a non-negligible part of faults in distribution network. So it is required that some measures are taken for isolating these faults.

\section{Literature Survey}

The Figure 2 shows that the first model of HIF was introduced in 1985, in this model the HIF was modelled by a single resistor in the fault location. After 5 years with respect to the presence of arc in the HIF, an arc based model is presented. In this model, the HIF is obtainable in anti-parallel two diodes, each one is series with a DC voltage source and series impedance the two diodes as well as the voltage sources show the diode voltage threshold. 3 years later, branch impedances were replaced with two nonlinear resistors. 


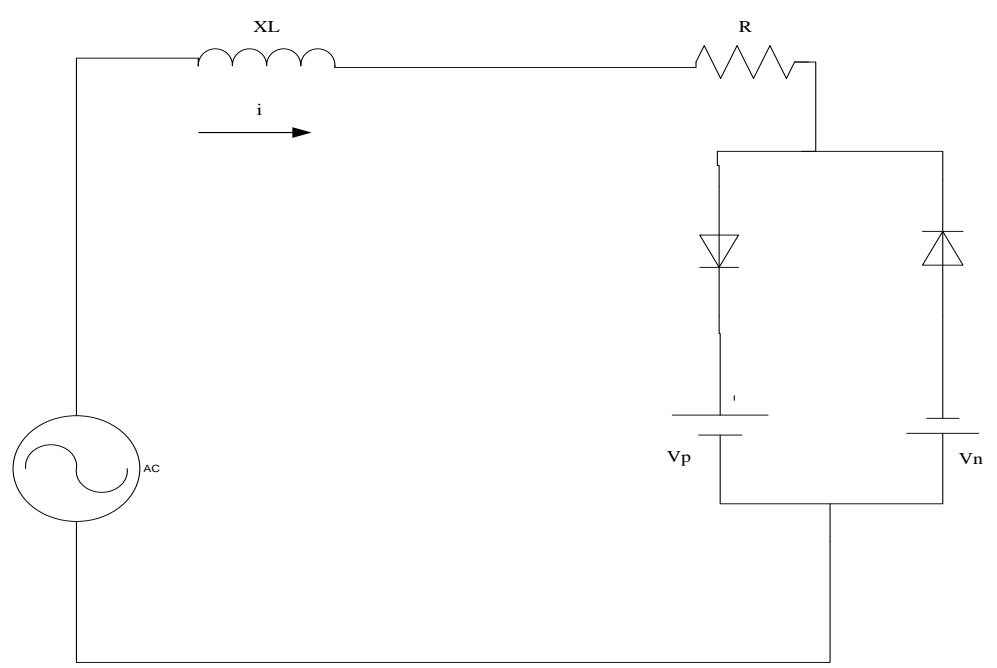

Figure 2. HIF Model Introduced by Emanuel [3]

In 2005 the arrangement of fixed and variable resistors in two half cycles were presented. In addition to the electrical aspects for HIF modelling, the dynamical aspects of the HIF arc are used. This is possible by using the dynamical relationships of electrical arc. A dynamical relationship is considered for a variable resistor placed in a path out of the diode routes. The benefit of this strategy is that the arc model results are close to the practical experiments. Also, in this model the routes of the two diodes can represented the nonsimilarity between positive and negative half cycle of high impedance fault, two voltage sources with random value were used to create random characteristics for the HIF current [3].

\section{Existing Methods}

Specialists have proposed different strategies for the identification and area of the HIF. These strategies typically begin by estimating accessible flag at the feeder and setting them up for examination. At that point the flag preparing devices are for highlight extraction and acquiring discriminative. The last has been utilized to segregate amongst typical and HIF circumstances. Fault detection and location is performed by using simple or intelligent Algorithms.

\subsection{Discrete Wavelet Transform (DWT)}

To discover the voltage signal harmonics and feeder current, in order to extract frequency feature of the HIF, some signal processing tools such as Fourier transform and kalman filter have been used. Additionally, the extent of the sounds was established through utilizing kalman channel, in the power system time-repetition based techniques are utilized. This reality is because of the time shifting conduct of the power system marvels particularly HIF. Figure 3 shows wavelet analysis is a signal-processing tool that has successful applications in various fields especially in power engineering. Some applications of the wavelet are in the field of power quality, power system protection, and power system transient. The DWT can be implemented by using a multistage filter with the mother wavelet as the low pass filter and high pass filter. The centre frequency is varied by changing the scale and time shift in the mother wavelet. This shows that the wavelet transform can suitably extract unwanted transient signals and frequency components of a waveform. There are different types of mother wavelets, which can extract specific features of the signal. It should be noted that the selection of the mother wavelet is important in feature extraction [4]. 


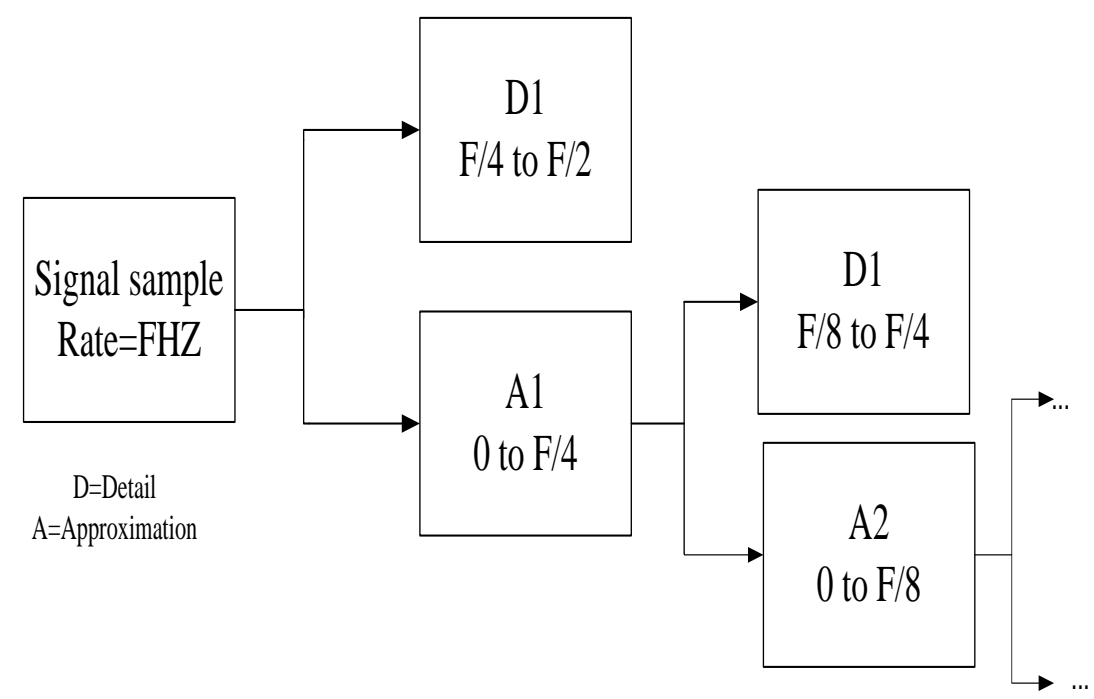

Figure 3. Analysis of Discrete Wavelet Transform from Level 1 to Level 2 [4]

This selection depends on the type of application. Suitable mother wavelet should have a greater difference between the normal and faulted output signal. Wavelet transform based technique for HIF detection in power distribution feeders. By using the DWT yields singlephase current and voltage in the low frequency range, which are fed to a classifier for pattern recognition. It is based on a moving window approach whereby the one-cycle window of the DWT output is moved continuously by one sample. Investigate the fault transient finders in light of computerized wavelet change are introduced at substation busbars and load terminals to catch the time taken for the transient to arrive and be synchronized with a worldwide situating system clock [5]. From time recorded and the topological structure, an exact fault area is accomplished. The fault area system is finished by utilizing EMTP on 11 KV appropriation lines with 7 tapped burdens. They accomplish exact and quick fault area strategy $[6,7]$.

\subsection{Artificial Neural Networks (ANN)}

ANN is one of the perceptive technique utilized for distinguishing to find the HIF in distribution system, ANN recognizes the data which makes it possible to find shortages. They require a inclination system to discover fault with a plan of data input and the ordinary. Figure 4 shows proposed work presents a strategy to recognize HIF for nonlinear arcing was proposed, later ANN-based technique without considering the fault initiation edge was proposed. The proposed work has been presents the technique considers fault protection and is free of the fault beginning point, it uses the crucial parts of pre-fault and post-fault positive arrangement segments of voltage and present as contribution for assessing the fault area. ANN has likewise been connected to find and distinguish HIF in dispersion system with DGs. This is because of HIFs are hard to be distinguished and found utilizing customary computerized handing-off. The proposed work presents, ANN utilizes two methodologies of discovering faults separation in distribution lines utilizing one-and twoend estimations. It utilizes course connection for fault discovery and was assumed that both methodologies perform similarly great in recognizing fault area. Likewise, it is noticed that course relationship utilizes less measure of input layer and less number of hidden layers compared with multilayer perceptron (MLP) [8]. 


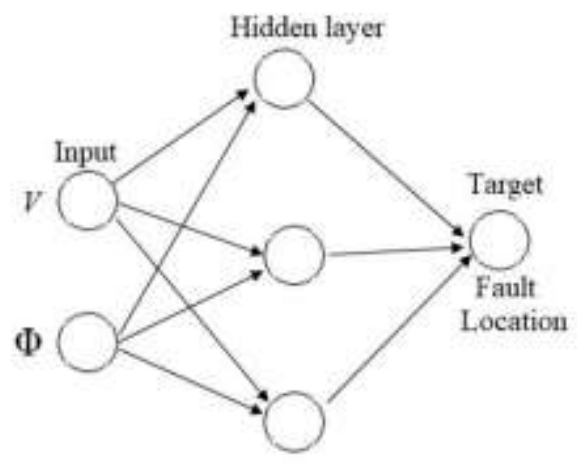

Figure 4. Basic Diagram of ANN [8]

A neural system was utilized to help the administrator in fault segment estimation control focus. The work depended on the activity data of circuit breakers and insurance hardware. For the determination, the insurance of transformers, busbars and distribution lines were demonstrated with two kinds of ANN; the multilayer perceptron and general deterioration neural systems. The test outcomes figured out how to adapt to changes in system arrange in genuine mass power system without preparing the systems once more. Sharaf, M. A. et al., (1993) has introduced an ANN-FFT based novel discovery conspire for HIFs in electrical conveyance systems. The plan utilizes a manufactured neural system (ANN) and uses a discriminant vector of major consonant succession extents of negative and zero (- , 0 ) parts of the supply voltages and streams at the substation. ANN calculation is a viable transferring plan that can be actualized utilizing accessible ANN equipment chips or programming. Arturo S. Bretas, (2006) has proposed a fault area gauges both direct impedance and non-straight HIFs. It utilizes constant information to recognize and find shortages. It can be assessed by an arrangement of qualities removed from the voltage and current signs estimated a substation [9].

The proposed technique is situated in the utilization of specific highlights of HIF and manufactured neural systems (ANN). While correlation with the proposed strategy, the Lee technique indicated better outcomes for direct faults, yet it prompts mistakes more prominent than $40 \%$ of HIFs. Thukaram et al., (2005) has proposes another joined approach, bolster vector machine (SVM) and fake neural system (ANN), sustain forward neural systems. These calculations gauge the obscure parameters in regulated learning. It demonstrates an extremely constrained and solid arrangement of estimations, it gives an exceptionally exact estimation of the fault area, notwithstanding, for an adjustment in organize design, following a possibility either the ANN must be retrained or an ANN prepared before possibility needs to put into benefit. SVMs attempt to discover the hyperplane. It isolates the preparation examples and classes, which have been beforehand mapped to a high dimensional space, with the end goal that basic hazard is limited. In, a technique utilizing nourish forward ANN was utilized to order and find faults in an appropriation organize. The technique utilizes fault voltage and current examples to find fault [10].

The proposed technique was tried for different fault composes, fault areas, fault protections and fault beginning edges. A most extreme rate blunder of 3\% was grown in the dissected experiments. ANN was tried in an IEEE 34-test feeder to device the fault separation of the substation. The information comprises of three-stage voltages, streams and dynamic energy of the feeder estimated at the substation in pre-fault and fault condition. The fault area, fault protection and burdens were changed in each working example. It was discovered that the prepared ANN figured out how to assess the fault separation to the substation effectively. The proposed strategy was likewise successful when the information was incorporated with estimation blunder. A back propagation system was executed in to 
recognize the kind of the fault. The repetition groups and energy dissemination at various minutes are removed by Hilbert-Huang change from hilter kilter ground fault. The technique utilizes zero grouping present as the information highlight of the system. It was discovered that the proposed strategy has enhanced the accuracy of various fault distinguishing proof, fault separation, establishing protection and fault time [11].

A mix of wavelet change and measured multilayer nourish forward neural system was exhibited in, which distinguished the fault kind and the area. Test outcomes demonstrate that the technique distinguished the broken stage and fault compose inside one process duration from the commencement of the fault. Fault separation was related to a most extreme mistake level of $0.688 \%$. In this way, the outcomes affirm the dependability and reasonableness of the proposed technique under various fault circumstances [11, 12].

\subsection{Support Vector Machine (SVM)}

Another technique is broadly utilized as a part of arrangement and deterioration systems which is picking up frequency among different clever procedures because of its execution. The quantity of help vectors for SVM is controlled by SVM calculation though in neural system, the quantity of hidden layers is verbalized by experimentation strategy. This improves SVM a grouping calculation than ANN. Figure 5 shows proposed work presents SVM was utilized to measure the fault kind and the fault separation of long distribution lines. It utilizes post fault single cycle current waveform to examine the fault. The upside of SVM is that it is speedier notwithstanding for vast estimated issue and require less heuristics. The primary highlights of SVM are the upper bond on the speculation mistake does not depend upon the measurement of the space. Abhishek Bansal et al., (2007) have introduced another technique to recognize HIF in spiral appropriation system. Extents of third and fifth consonant parts of voltages and streams are utilized as a component vector for fault separation.

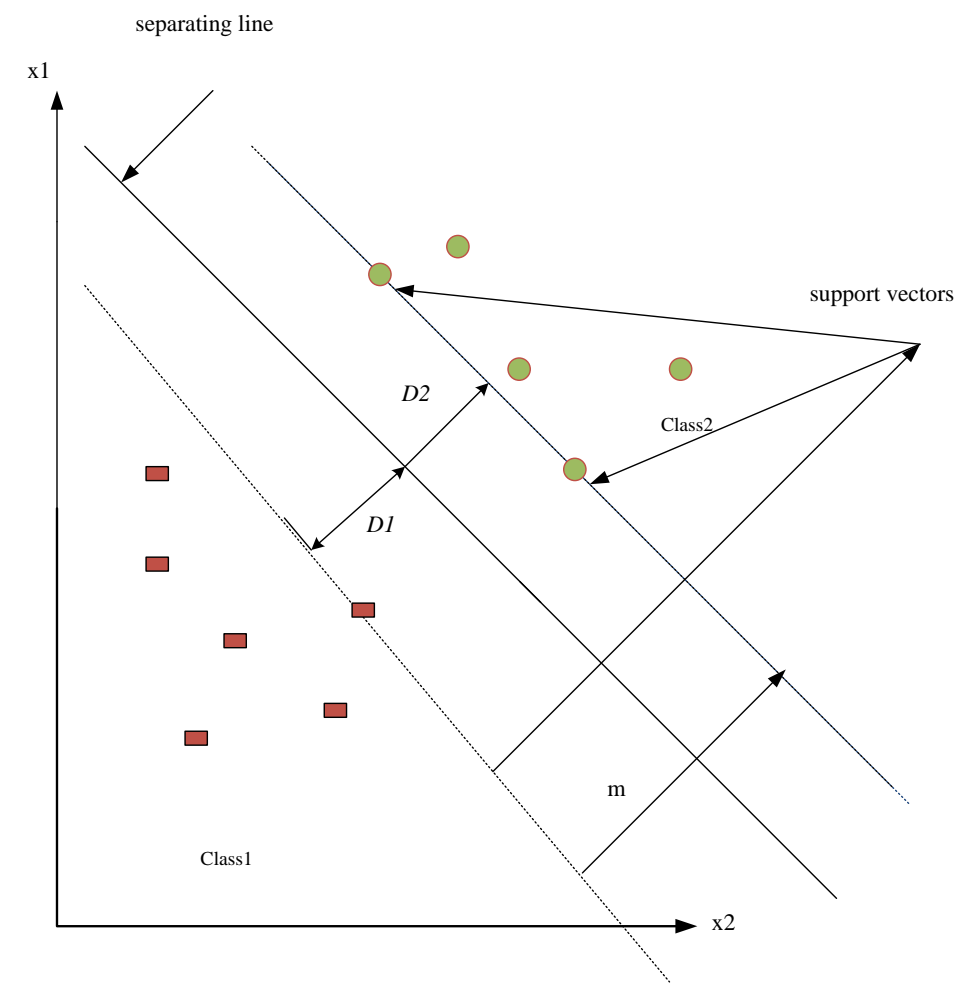

Figure 5. HIF Detection using SVM based on Best Line Separating $x 1$ and $x 2$ [13] 
By diminishing the quantity of preparing vectors, the contrast amongst RBF and SVM classifiers develops for SVM. This demonstrates the SVM organize has acceptable speculation capacity and could perceive lists and different unsettling influences effectively, for the extensive variety of variable parameters. An analysis was made between RBF neural system and SVM, which demonstrates neural system has a disorder of limiting mistake work by influencing the learning procedure. SVM has likewise been connected for fault characterization in distribution lines. The proposed work introduced, data got from the wavelet disintegration of post fault current signs was utilized as the contribution to SVM for arrangement of fault kind in distribution lines. The proposed strategy was tried on a 240 $\mathrm{kV}, 200 \mathrm{~km}$ distribution line under various sorts of fault and system factors, for example, fault protection, fault separation and fault beginning point. The outcomes demonstrate that the proposed procedure was exact and powerful for different system parameters and fault conditions. SVM was utilized as a keen device in to separate between various zonal component faults in distribution system [13].

The strategy utilizes clear impedance regards from separate transfer at various fault conditions. The strategy was effective for various working conditions and fault protection esteems. Another work additionally utilizes SVM for a distribution line with arrangement repaid utilizing a settled capacitor set at the focal point of the line to characterize a fault. The examples of each zero arrangement current and line current are the info highlights of SVM, which order the relating issue. The strategy was tried on a $400 \mathrm{kV}$ distribution line for various fault protections, fault position, fault origin points, rate remuneration levels, pre-fault power exchange levels and source impedance esteems. Test outcomes show that the proposed method is quick, exact and strong. A hybrid approach utilizing wavelet change and SVM was proposed in for exact fault area in distribution lines. The voltage and current signs toward one side of the distribution system were utilized as a part of to find a fault. It works in three phases. Initially, wavelet change was utilized to remove the high repetition segments of voltage and current. Also, fault compose was distinguished utilizing bolster vector characterization. At long last, the fault separation was recognized utilizing bolster vector relapse investigation. The precision of fault kind distinguishing proof is $1 \%$ and $0.7 \%$ for fault separation. The restriction of the technique is that it doesn't think about the defective stage in the system [14].

The technique in recognizes the faulted segment and fault separation. The defective area was distinguished utilizing the zero arrangement current variety when shutting the switch in ring system. The strategy likewise uses wavelet change to extricate eigenvalues from zero arrangement current. The extricated esteems are then prepared utilizing SVM to distinguish the fault separation. The proposed strategy was broke down just for single stage establishing deficiency and isn't appropriate for different sorts of fault. The proposed work presents, SVM was utilized to evaluate the fault kind and the fault separation of long distribution lines. It utilizes post fault single cycle current waveform to investigate the fault. The highlights are gathered by wavelet bundle change and the excess highlights are expelled through forward component choice technique. The test information are analysed by SVM in which the parameters are advanced by molecule swarm improvement technique. The reproduction comes about yield most extreme fault grouping precision and negligible fault position blunder $[15,16]$.

\subsection{Genetic Algorithm (GA)}

GA is a smart strategy that can likewise be utilized to find and recognize the fault, the technique looks through the conceivable fault area through determination, hybrid and change activities to distinguish the correct area. An approach for the faulty area estimation utilizing. Figure 6 shows Fuzzy inference system (FIS) based on GA was proposed. Another strategy utilizing GA was proposed in, membership functions (MFs) which partitions the dissemination system into principle branch and into singular areas. The autonomous districts are identified utilizing deficiency current and GA was utilized to discover the fault 
for the fundamental branch and fault free locations. This strategy is reasonable for single fault or complex fault area of single power source. A fault area strategy utilizing GA for distribution lines was proposed. It utilizes line parameters at the two terminals of the line to distinguish the fault area. The strategy was tried with the real fault account information got from the south matrix of china. The benefit of this technique are the reproduction speed can be improved and the measurement of conceivable arrangements can be diminished [17].

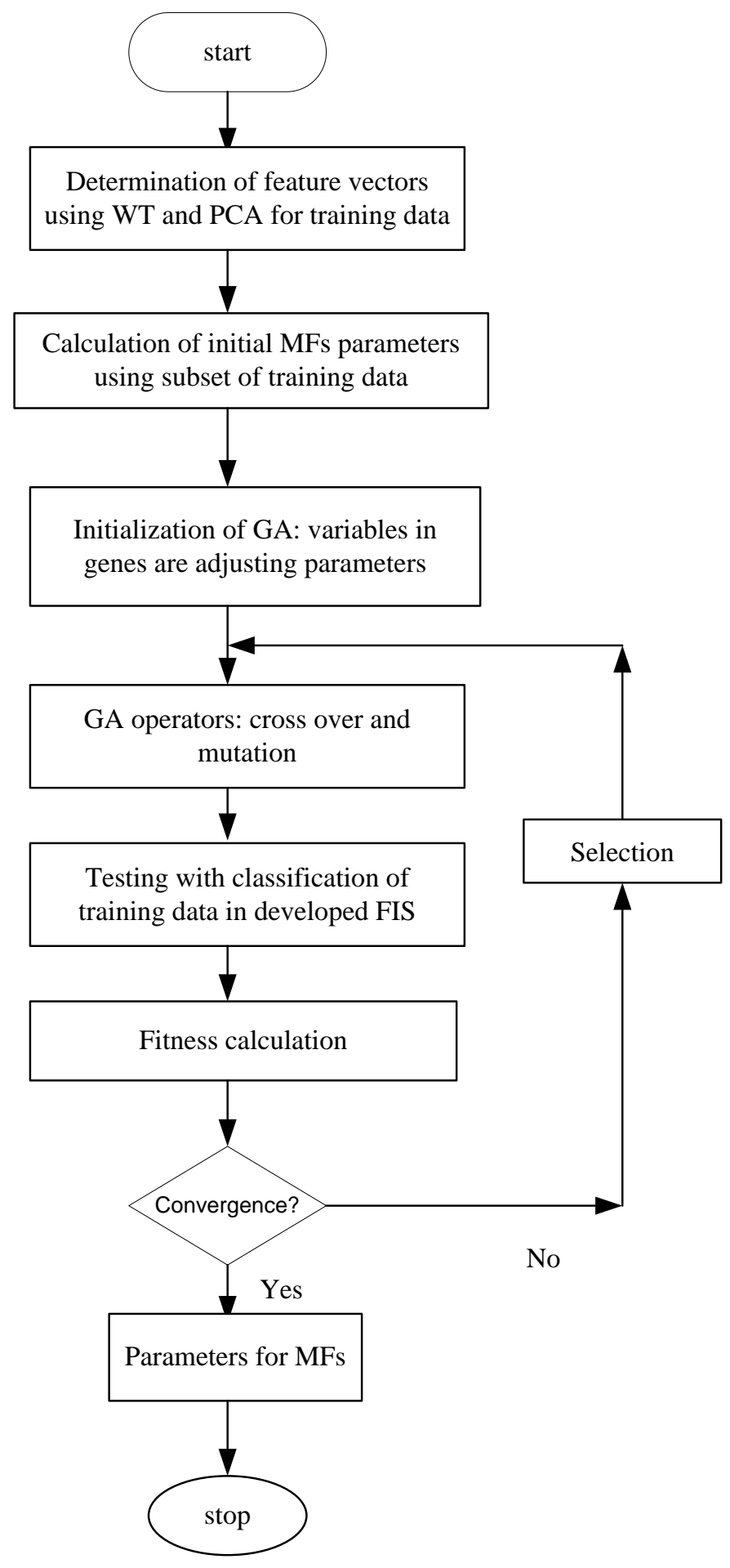

Figure 6. FIS based on GA for HIF Detection [17] 
An approach for defective area estimation utilizing GA was proposed. In this work, the faulted area estimation is allocated with as an enhancement issue. The target work is distinguished utilizing Hebb's control and utilized by Continuous Genetic Algorithm (CGA) enhancement for defective area identification. The proposed work decreases the time required by CGA to distinguish the faulted area. The technique utilizes less capacity and is speedier than Binary GA. Hereditary Algorithm and wavelet change were applied as a part for fault arranging of three-stage distribution lines. The technique utilizes three-stage streams toward one side of distribution line for fault identification. The highlights are removed utilizing discrete wavelet change and utilized as contributions to GA. The proposed strategy characterizes fault with a most extreme blunder level of $7 \%$. The benefits of this technique are the reproduction speed can be upgraded and the measurement of possible arrangements can be decreased. The impediment of GA for fault area in transmission system is the outcomes are not reliable after some time in light of the fact that in GA, all procedures are arbitrary [18]. In this work another HIF location strategy in light of the wavelet change for highlight extraction, and vital part investigation for the determination of highlights, and a fuzzy inference system for basic leadership is introduced. Likewise, a hereditary calculation of GA is utilized to change the MFs at the preparation arrange. In this exploration HIF information was assembled from a $20 \mathrm{kV}$ extended distribution feeder in a genuine system [19]. Information for other transient occasions was created by re-enactment of this $20 \mathrm{kV}$ appropriation feeder utilizing EMTP. The fundamental component in the procedure utilizing 60 vectors, half of the accessible information, MFs for four sources of info are balanced for most elevated exactness in grouping. As expressed, every MF has three parameters $\left(\mathrm{u}_{1}, \mathrm{u}_{2}\right.$, and $\left.\mathrm{u}_{3}\right)$ and every one of them is changed in accordance with get an appropriate state of the MFs. Point of this modifying procedure is right order of FIS for the preparation information. There are three parameters for every MF, four MFs in each lead and three principles. Along these lines it is important to change 36 parameters for the arrangement of every one of the 12 input MFs. This may require vast calculation time. To defeat this issue, the utilization of a GA is proposed [20, 21].

\subsection{Fuzzy Logic Technique}

Fuzzy logic-based demand scheme was proposed in, which recognized the kind of fault in distribution structures. Figure 7 shows proposed work explains a, higher demand experiences were made to isolate the features of fault signal and to group the fault using fuzzy logic. Using line current estimation of every one of the 3 phases was proposed. A while later, the methodology was created in for fault type in unequal structures. Fuzzy system and synchronized Phasor estimation was used as a piece of to recognize the fault type and faulted region in double circuit distribution lines. The procedure orders plan, shunt and shunt defects. Test results show that the faulted territory screw up rate is inside $1 \%$ for plan fault and is up to 5\% if there ought to emerge an event of shunt fault. An approach for faulted acknowledgment and request in light of fuzzy logic and Programmable Automation and Control development was displayed. The three phase pivoting present, zero progression and positive course of action current data are made and taken care of clearly to hand-off. The results exhibit that the proposed strategy is set up to do right faltering action and can give customized security continuously [22]. 


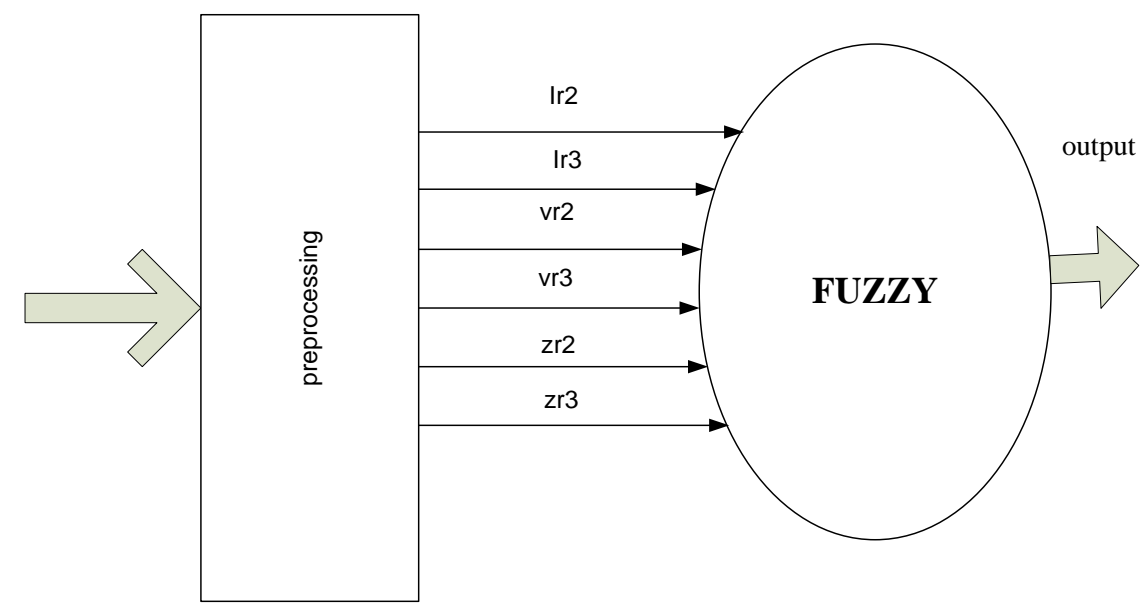

Figure 7. HIF using Fuzzy Logic [22]

Yet fuzzy logic-based arrangement is exceptionally adequate, the drawback of fuzzy logic is in choosing the overall slightest using fuzzy enlistment limits. Similarly, feature definition and extraction must be updated for portrayal estimation. Fuzzy system and synchronized Phasor estimation was used as a piece to perceive the faulted sort and faulted region in twofold circuit distribution lines. The method describes plan, shunt and simultaneous course of action shunt blemishes. Test results show that the faulted region mix up rate is inside $1 \%$ for plan fault and is up to 5\% if there ought to emerge an event of shunt fault. An approach for faulted distinguishing proof and request in perspective of fuzzy logic and Programmable Automation and Control development was displayed. The three stage exchanging present, zero succession and positive arrangement current information are produced and handled straightforwardly to relay. The outcomes demonstrate that the proposed method is prepared to do right stumbling activity and can give programmed security continuously. Albeit fuzzy logic-based plan is very acceptable, the disadvantage of fuzzy logic is in deciding the worldwide least utilizing fuzzy participation capacities. Likewise, highlight definition and extraction must be improved for arrangement calculation $[23,24]$.

Fault happens because of disappointment of protection of the dissemination system, crossing over of invigorated stage conductors by objects, mishaps and so forth. These occasions influence the estimation of the voltage and current on the conveyance system and once in a while the whole power system. Considering the way that most circulation system are run overhead and have an outspread topology, the requirement for exact and dependable fault discovery system ends up convenient. As of late, specialists are more intrigued by discovering answers for the issue of dubiousness, deficient fault data, mistake in fault information and data repetition. "The utilization of fuzzy logic empowers the fault recognition system to adapt to vulnerabilities that happen amid the area of fault in electrical appropriation systems". The proposed work introduced fault discovery strategy utilized fuzzy logic-based calculation to distinguish ten sorts of shunt faults in spiral, uneven dispersion system. The parameters utilized incorporate fault protection, fault beginning edge, system topology and stacking levels. A half breed approach of neuro-fuzzy based learning and fault order approach in light of the web based learning system was proposed [25].

In this work, a technique for fault area in light of the regular disconnected neuro controller approach is contrasted and the proposed half breed approach for learning and merged time assessment for circulated system. The proposed work Presents a smart fault area and determination system. This system performs fault compose recognizable proof utilizing a two-advance method. The initial step distinguishes competitor fault area utilizing an iterative computation of the heap current and the fault current. The second step analysed 
the real area of the fault by contrasting the present waveform design and the normal activity of the defensive gadgets and contrasting the intruded on stack and the genuine load. They performed different recreations to get an acceptable outcome. Presents a technique for fault conclusion in view of a chain of command of five operators that collaborate with each other to analyse a fault. The proposed work presents a broadened impedance-based fault area definition for summed up circulation system was proposed. This technique utilizes just neighbourhood voltages and streams as information. The plan considers stack variety impacts and diverse fault writes [26, 27].

\section{Comparison of Artificial Intelligent Techniques and Wavelet Technique}

Table 1. Comparison of Intelligent and Simple Techniques

\begin{tabular}{|c|l|l|}
\hline Techniques & \multicolumn{1}{|c|}{ Advantages } & \multicolumn{1}{c|}{ Disadvantages } \\
\hline DWT [4]-[7] & $\begin{array}{l}\text { It gives exact time and repetition comes about } \\
\text { when contrasted with different systems. }\end{array}$ & $\begin{array}{l}\text { The adaptability of DWT is } \\
\text { here and there extremely hard } \\
\text { to pick which premise is to } \\
\text { utilize. It is harder to translate } \\
\text { the outcomes. }\end{array}$ \\
\hline ANN [8]-[12] & $\begin{array}{l}\text { Effortlessness in usage. Recognizes the } \\
\text { nonlinear connection amongst needy and free } \\
\text { factors. }\end{array}$ & $\begin{array}{l}\text { Reliant on the sum and nature } \\
\text { of the prepared information in } \\
\text { creating an all-around prepared } \\
\text { ANN calculation. Preparing } \\
\text { process has moderate merging. }\end{array}$ \\
\hline SVM [13]-[16] & $\begin{array}{l}\text { It is speedier notwithstanding for vast size } \\
\text { issues and requires less heuristics. }\end{array}$ & $\begin{array}{l}\text { The impediment is in picking } \\
\text { bit work and hyper. Which } \\
\text { gives the best speculation } \\
\text { execution. }\end{array}$ \\
\hline GA [17]-[21] & $\begin{array}{l}\text { Reproduction speed can be upgraded and the } \\
\text { measurement of conceivable arrangements can } \\
\text { be lessened. }\end{array}$ & $\begin{array}{l}\text { The consequences of fault area } \\
\text { are not predictable after some } \\
\text { time in light of the fact that in } \\
\text { procedures are }\end{array}$ \\
\hline FLT [22]-[27] & $\begin{array}{l}\text { GA, all } \\
\text { irregular. }\end{array}$ \\
\hline creating rules.
\end{tabular}

\section{Conclusion}

This work explored the huge majority of the methods that have been produced since the past and commonly used to detect and locate the HIFs in power distribution systems with distributed generation. The basic principles, advantages, disadvantages and review of past works related to each technique have been studied. The adequacy of every technique represented has additionally been assessed. In general, HIF detection and location methods in distribution systems can be divided into two categories, conventional methods and artificial intelligence methods. The advantages of conventional HIF location and detection methods are simple measurement setup and less time is required for computation. However, their disadvantages are they can be inaccurate for too large power system networks. Each 
method suits a problem depending on the complexity of the network and the availability of monitoring devices.

\section{References}

[1] S. H. Mortazavi, Z. Moravej and S. M. Shahrtash, "A hybrid method for arcing faults detection in large Distribution networks", International Journal of Electrical Power \& Energy Systems, Elsevier, vol. 94, no. 16, (2018) January, pp. 141-150.

[2] Z. Liang "High impedance fault detection in power distribution systems with impedance Based methods in frequency domain", Ph.D. Thesis, Sun Yat-sen University, (2016) October.

[3] A. Emanuel, "High impedance fault arcing on sandy soil in $15 \mathrm{KV}$ distribution feeders: contributions to the evaluation of the low frequency spectrum", IEEE Transactions on Power Delivery, vol. 5, no. 2, (1990) April, pp. 676-686.

[4] M. Banejad, "High impedance fault detection: Discrete wavelet transform and fuzzy function approximation", Journal of AI and Data Mining, vol. 2, no. 2, (2014) June, pp. 149-158.

[5] M. F. Akorede, "Wavelet Transform Based Algorithm for High- Impedance Faults Detection in Distribution Feeders", European Journal of Scientific Research, vol. 20, no. 2, (2010) September, pp. 237 247.

[6] T. M. Lai, "High-impedance fault detection using discrete wavelet transform and frequency range and RMS conversion”, IEEE Transactions on Power Delivery, vol. 20, no. 1, (2005) April, pp. 397-407.

[7] A. R. Sedighi, "High impedance fault detection based on wavelet transform and statistical pattern recognition", IEEE Transactions on Power Delivery, vol. 20, no. 4, (2005) September, pp. 2414-2421.

[8] S. S. Gururajapathy, "Fault location and detection techniques in power distribution systems with distributed generation: A review", Renewable and Sustainable Energy Reviews, vol. 74, pp. 949-958, (2017) April.

[9] A. M. Sharat, "A neural network based back error propagation relay algorithm for distribution system high impedance fault detection", 2nd International Conference on Operation and Management in Advances in Power System Control, vol. 2, no. 1, (1993) June, pp. 613-620.

[10] A. S. Bretas, "A novel high impedance fault location for distribution systems considering distributed generation", In Transmission \& Distribution Conference and Exposition: Latin America, (2006) August, pp. 1-6.

[11] D. Thukaram, "Artificial neural network and support vector machine approach for locating faults in radial distribution systems", IEEE Transactions on Power Delivery, vol. 20, no. 2, (2005), pp. 710-721.

[12] B. Vahidi, "An Approach to Detection of High Impedance Fault Using Discrete Wavelet Transform and Artificial Neural Networks. Simulation”, IEEE Transactions on Power Delivery, vol. 86, no. 4, (2010), pp. 203-215.

[13] R. Salat, "Accurate fault location in the power distribution line using support vector machine approach", IEEE Transactions on power systems, vol. 19, no. 2, (2004), pp. 979-986.

[14] P. Janik, "Automated classification of power-quality disturbances using SVM and RBF networks", IEEE Transactions on Power Delivery, vol. 21, no. 3, (2006), pp. 1663-1669.

[15] U. B. Parikh, "Fault classification technique for series compensated distribution line using support vector machine", International Journal of Electrical Power \& Energy Systems, vol. 32, no. 6, (2010), pp. 629636.

[16] S. Ekici, "Support Vector Machines for classification and locating faults on distribution lines", Applied Soft Computing, vol. 12, no. 6, (2012), pp. 1650-1658.

[17] Y. Li, "A fault location method based on genetic algorithm for high-voltage direct current transmission line", Eur Trans Electr Power, vol. 22, (2012), pp. 866-78.

[18] PP. Bedekar, "Fault section estimation in power system using Hebb's rule and continuous genetic algorithm", Int J Electr Power Energy System, vol. 33, (2011), pp. 457-65.

[19] Q. Jin and R. Ju, "Fault location for distribution network based on genetic algorithm and stage treatment", Proceedings of the spring congress on engineering and technology (S-CET), (2012), pp. 1-4.

[20] M. R. Haghifam, "Development of a fuzzy inference system based on genetic algorithm for highimpedance fault detection", IEE Proceedings-Generation, Transmission and Distribution, vol. 153, no. 3, (2006), pp. 359-367.

[21] Stevenson Junior WD, Elements of Power Systems Analysis, McGraw-Hill International, 3rd edition, (1982).

[22] A. NS Shuma and D. Thingam, "Fuzzy logic based on-line fault detection and classification in transmission line", Springer plus, vol. 5, (2016).

[23] W. C. Santos, "High impedance fault detection by using wavelet and fuzzy inference system", International Conference on Power Systems Transients Vancouver, Canadá, (2013) July, pp. 18-20.

[24] M. R. Haghifam, "Development of a fuzzy inference system based on genetic algorithm for high impedance fault detection", IEEE Transactions on Smart Grid, vol. 6, no. 2, (2005), pp. 894-902.

[25] B. Das and J. V. Reddy, "Fuzzy-logic-based fault classification scheme for digital distance protection", IEEE Trans Power Delivery, vol. 20, (2005), pp. 609-16. 
[26] F. G. Jota and P. R. S. Jota, "High-impedance fault identification using a fuzzy reasoning system", IEEE Proceedings-Generation, Distribution and Distribution, (1998), pp. 656-662.

[27] N. Kumar, "Fault Detection on Radial Power Distribution System using fuzzy logic", (2015).

\section{Authors}

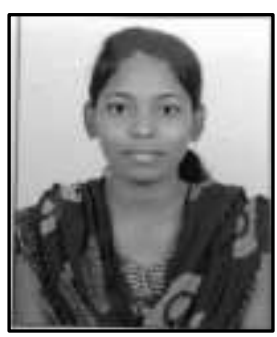

Gogula Vyshnavi was born in Andhra Pradesh, India, on January 24, 1994. She received her B.Tech degree in Electrical and Electronics Engineering from JNTU Anantapuramu in 2015. At present, she is pursuing M.Tech in Electrical Power System at the Department of Electrical and Electronic Engineering in Sree Vidyanikethan Engineering College, Andhra Pradesh, India. Her main research interest is power system protection, distributed generation, specifically detection and location faults in distribution system.

Avagaddi Prasad was born in India in 1989. He received his B.Tech degree in Electrical and Electronics Engineering from JNTU Kakinada, Andhra Pradesh, India in 2011. M.Tech degree in Power Systems and Automation from GITAM University, Andhra Pradesh, India in 2013 and PhD degree in School of Electrical Engineering from VIT University, Tamil Nadu, India in 2017. He worked as an Assistant Professor in department of Electrical and Electronics Engineering, VITS College of Engineering, Andhra Pradesh, India from June, 2013 to June, 2014. $\mathrm{He}$ is currently working as Associate Professor in department of Electrical and Electronics Engineering, Sree Vidyanikethan Engineering College, Andhra Pradesh, India. His major scientific interest is focused on power system protection, fault analysis, power quality, and soft computing techniques. 
International Journal of Advanced Science and Technology Vol.119 (2018) 